\title{
Diversity among Post Graduate Certificate in Education Students during a Yearly Educational Excursion in a University in Gauteng Province, South Africa
}

\author{
Dr M. Sedibe \\ Department of Educational Psychology, University of Johannesburg, P.O. Box, 524. \\ Aucklandpark.Johannesburg.2006. South Africa \\ mabathos@uj.ac.za
}

\section{Doi:10.5901/mjss.2014.v5n20p1434}

\begin{abstract}
This article focuses on describing diversity among Post Graduate Certificate in Education (PGCE) University students from different backgrounds, using educational activities such as egg, shoe string and solar heating as activities. The aim of this study is to describe diversity among PGCE University students during an educational excursion in 2014. Qualitative research method was used and also data was collected through informal observation. One hundred and fourty PGCE students were informally observed by the researcher during their stay at Achterbergh. The findings of this study indicated that the educational activities done by these students were of value. The reason being that they became aware of the importance of friendship, respect, self-awareness, improved social interaction, improved relationships, cultural and language barriers.
\end{abstract}

Keywords: Educational Excursion, diversity, Post Graduate Certificate in Education

\section{Introduction and Background of the Study}

This paper is based on the exploration, description and findings from the educational excursion under-taken by PGCE University diverse students in 2014. Some lecturers and the researcher accompanied the PGCE Senior and Further Education and Training phases (FET) University students to Achterbergh in the Gauteng province. The purpose was to observe how these students interact with one another as they perform educational activities such as egg, shoe string and solar heating ,just to mention but a few. Educational excursion in this study is described by (Mchie, 1998), (Rahman \& Spafford, 2009) as a trip arranged and undertaken for educational purposes. The researcher adds by explaining that educational excursion is a formal trip undertaken by a group of people to a place away from their normal environment/institution, with an aim of gaining a specific learning experience. The educational excursion is undertaken yearly at this University with an aim of enhancing diversity among diverse students, coming from different backgrounds using different educational activities from the modules taught at the University.

Post Graduate Certificate in Education on the other hand is described by the researcher as the specific qualification available for those who want to enter teaching profession after obtaining their undergraduate degree.

From South African Education system perspective, Senior and Further Education and Training (FET) phases were in the past prior 1994, falling within standard 7 to 10 .

The mixed group of diverse students was about one hundred and fourty, consisting of different cultural, political, social, racial, ethnic, linguistic and economic background hence diverse students. This composition of students according to (Sen-Gupta , 2003) is understood to be people of different cultures. In this study, this means that teachers, lecturers and students should understand and appreciate human diversity irrespective of their cultural, socio-economic backgrounds the demographic locations of individuals. On this note, the researcher therefore describes diversity as the appreciation, understanding and respect for cultures, thus overcoming ethnocentricity and discrimination. This means that as teachers and students we should not ignore the issue of diversity in any educational teaching setting. This implies that we should arrange educational activities in such a way that they will enable students to share, care and love other peoples' culture.

Based on the above description, the researcher thus opted to employ a qualitative generic ethnographic design. This method is relevant to this study because the researcher will observe students' during their educational activities derived from the learning guide given to them on site with an aim of seeing how these students enhance diversity in their interaction.

It is on this note that the researcher describes an educational excursion under-taken by one hundred and fourty 
Post Graduate Certificate in Education (PGCE) University diverse students in 2014. The educational excursion is undertaken yearly at this University with an aim of enhancing diversity among diverse students, (consisting of different cultural, political, social, racial, ethnic, linguistic and economic background), using different educational activities from the modules taught at the University.

Some lecturers and the researcher accompanied the PGCE Senior and Further Education and Training phases (FET) University students to Achterbergh in the Gauteng province, South Africa. The purpose was to observe how these diverse students interact with one another as they perform educational activities. An activity on an egg was given to each newly formed diverse group of students. They were supposed to cover that egg with a balloon and paper in such a way that if it is thrown on to the floor it should not break. When the activity was performed, the group of students started to interact with each other, aiming at achieving the desired goal of seeing to it that the egg does not break. Educational excursion in this study is described by (Rahman \& Spafford, 2009) as a trip arranged and undertaken for educational purposes. The researcher adds by explaining that educational excursion is a formal trip undertaken by a group of people to a place away from their normal environment/institution, with an aim of gaining a specific learning experience.

The above composition of students according to (Sen-Gupta, 2003) is understood to be people of different cultures. In this study, this means that teachers, lecturers and students should understand and appreciate human diversity irrespective of their cultural, socio-economic backgrounds the demographic locations of individuals. On this note, the researcher therefore describes diversity as the appreciation, understanding and respect for cultures, thus overcoming ethnocentricity and discrimination. This means that as teachers and students we should not ignore the issue of diversity in any educational teaching and learning setting. This implies that we should arrange educational activities in such a way that they will enable students to share, care and love other peoples' culture.

Based on the above discussion, the researcher thus opted to employ a qualitative generic ethnographic design. This method was used with an aim of obtaining more information about diversity in PGCE university students during their educational excursion. Data was collected through observation method. Students were observed during their educational activities derived from the learning guide given to them on site with an aim of seeing how these students enhance diversity in their interaction. From this study the researcher for example found that students were able to get out of their comfort zone and enter the unfamiliar surroundings. While answering the questions, students gradually became relaxed and also laughed. That broke the tension between diverse students but all in all, it became an enjoyable experience. On this note it can be concluded that Institutions of Higher Learning should include more learning content in the learning guides on diversity and also conduct more work-shops to teachers and student teachers on how to interact with different children/learners and different communities.

\section{The Purpose of the Faculty of Education's Yearly Educational Excursion}

The purpose of the educational excursion at this University is to assist different students from different backgrounds, race, ability, culture and religion to work together in educational activities given by different lecturers from their modules. These activities are always planned before the commencement of the educational excursion and they are in line with the University module's outcomes with its theoretical framework that focusses on ethos of care, accountability, embracing diversity, critical reflection and also being a researcher. From the module of the methodology of Life Orientation (LO), consisting of four Learning Outcomes i.e. (personal well-being, citizenship education, recreation and physical well-being and career and career choices) as written in the National Curriculum Statement of 2004, the researcher chose to facilitate and focus on a case study entitled Professional boundaries from the book "Being a Teacher, a book of Cases", edited by (Gravett, Merseth \& de Beer , 2013). The case study allowed students to use their various skills such as collaboration, respect, communication, planning, time management, creative and critical thinking skills in answering these two questions. 1. "Put yourself in Themba's shoes. Should he have changed his pedagogy, based on the discussion that he had had with Mr Masemola? 2. Do you agree with the Principal's view that Themba overstepped boundaries with the Aids game?. Students were able to use discussion, question and answer methods in attempting to answer the above questions. Through these methods students were able to closely interact and form groups that helped them in giving answers to the entire group.

On this note, one can still prematurely further emphasize that the purpose of this article is to describe the extent to which the educational excursion can attempt to promote students' embracement of diversity at the University using activities that would give them chance to inter-relate and respect one another. Also to share their views, leave their familiar, unfamiliar comfort and discomfort environments and create a mostly non-conflicting and conducive atmosphere. 


\section{Research Question}

Research question for this study is:

How can diversity be described among PGCE students during a yearly educational excursion in Gauteng province?

\section{Aim of the Study}

The aim of this study is to:

Describe diversity among PGCE students during a yearly educational excursion in Gauteng Province.

\section{Theoretical Framework}

The framework within which this study is based on, is Vygotsky's socio-cultural (social interaction) theory. This theory plays a fundamental role in the development of cognition through mediation as (Vygotsky, 1978) states that every function in the child's cultural development appears twice: first on the social level, and later on the individual level i.e. (first, between people (inter-psychological) and then inside the child, (intra-psychological). Brofenbrenner's theory is also important in this study as it focuses on the interrelated systems such as the family, school, and society. These theories are therefore relevant to this study and their relevance is seen when as a lecturer and researcher has mediated and interacted formally and informally with these students from different family backgrounds and different cultural backgrounds during the time when they were attempting to read, interact, discuss and answer the questions. It can be once more emphasized that the preceding theoretical frameworks are relevant to this study, as we are in the currently changing education system that needs constant positive interaction between individuals and systems such as individuals, families, schools and communities. This implies that interaction can be viewed as an important concept that has a positive connotation, as in this study can lead to the students' respect to one another.

\section{The Context of Diversity in this Study}

There is a widely held misconception about diversity, that people think it is static. Some people think it deals with learning about all the historically under- represented groups in the society or community. In this study diversity is viewed as the concept that encompasses acceptance and respect of an individual's race, ethnicity, gender, sexual orientation, socioeconomic status, age, physical abilities, religious beliefs and political beliefs. In addition people ask teachers to show the type of teaching method they can employ to such a group. This is not the case in this study as students should be taught to know that diversity has been at a centre of debate in South Africa. Achieving it remains a challenge because of South Africa's complex political, geographic and socio-economic factors. This does not mean that we should postpone seeking ways in which diversity can be enhanced in the various teaching and learning settings. This is further supported by for instance (Banks,1989) when pointing out that we should strengthen an awareness of diversity by shifting away from the traditional view and work not with diverse students only but also co-operate and communicate with their parents from diverse and socio-economic backgrounds. That is the reason why the theoretical framework of eco-systemic perspective is also relevant to this study as it focuses also on the interaction with the families (micro-system), schools (meso-system) and societies (macro-system).

\section{The Concept of Case Study in this Study}

Case study is defined by (Crowe, Cresswell, Robertson, Huby, Avery \& Sheikh, 2011), as an approach that allows indepth, multi-faceted explorations of complex issues in their real-life settings. In this study the researcher can further add that case study is a dynamic unique knowledge building system method which was ignored and neglected in the past by teachers as it was being viewed as a waste of time. It is dynamic because new knowledge is continuously emerging during the students' discussion and also added and stored in their memories for future use. Case study method is thus useful to employ when there is a need to obtain and provide an in-depth insights and appreciation of an issue and event or phenomenon that may be learnt. To support the above statements, students were expected to use their communication, respect, planning, timing, team-work, creative and critical thinking skills to solve the problem in that given case study activity.

As mentioned in the previous section, the case study with its activities emphasized teamwork with an aim of 
promoting diversity. In other words it can be stated that teamwork is the process of working collaboratively with a group of people (in this study a group of students) in order to achieve a desired goal. This is supported by ( Leonard, Graham \& Bonacum , 2004) when mentioning that teamwork is aimed at creating a common mental model ... creating an environment that feels "safe" to team members so that they will speak up when they have safety concerns. This means that case study activities can promote diversity because in it participants can learn to respect and work together as a team. This was also seen in this study when students thought, planned ahead and discussed as well as having an ongoing dialogue, which kept members of their teams actively involved. Given such a preceding description, the researcher therefore is of the opinion that such involvement encouraged them to collaboratively work harder thus enhancing positive competition among the students without looking at the skin colour, language, social class and culture of the individuals.

\section{Research Design and Method}

This study used a qualitative research method, which involves an engagement with the participants as stated by (Merriam, 2002). In qualitative research, (Henning, Van Rensburg and Smit, 2004) add that phenomena are studied in their natural settings. That is the reason why the researcher firstly wanted to make sense in terms of students' interaction with others during the reading and discussion of the case study based on "There is a professional boundary, and you, young man, have overstepped it". The design adopted is generic ethnographic because one hundred and fourty students were intensely observed formally and informally for two days by the researcher in the educational setting. This was done when they discussed and answered questions from the case study, with an aim of seeing how they interact with one another. This means that the researcher used observation as a data collection instrument and thus observed them as they interact with other students from different cultures, race, language, ethnic group and social class.

\section{Data Collection and Analysis}

Data was collected through informal and formal observation for two days by the researcher during the time when the total group of one hundred and fourty PGCE University students were interacting with one another as they read, discussed and answered two questions derived from the case study as mentioned in the preceding section. The researcher thus constantly monitored and kept a detailed record of what he/she observed in the journal. (Mouton , 2001) describes data analysis as the breaking up of data into themes, patterns and relationships.

Data was thus analyzed by means of content analysis where the researcher used observation notes. Content analysis is thus relevant to this study because (Henning et al., 2004) describe it as the process of transcribing and coding themes that emerge from the categories. In this study, the researcher also described these themes in detail.

\section{Limitations of the Study}

This study was limited to only PGCE student teacher at the University, and therefore cannot be generalized to other cases or similar situations. Secondly the research i.e. observations were conducted over a limited period of time. The findings could have been expanded had the research been carried out over a longer period

\section{Discussion of the Results}

The aim of the educational excursion and outcome of the case study activities were to achieve the enhancement of diversity among different PGCE university students. What evidently came out from the study was that the students were ultimately able to successfully interact with one another; hence diversity was accomplished. This was seen when the researcher observed students during their interaction with one another, showing that closenesses and working together as teams as well as sharing ideas related to case study activities. This was shown when at the end of the activity, these students were able to discuss together and that led to the development of positive interaction. Positive interaction according to (Dutton \& Heaphy, 2003) and ( Miller \& Stiver, 1997) means the interaction between two or more people and are mutually aware of the interaction.

The researcher is also in support of the increased positive interaction of students at the university as it will assist in promoting the acknowledgment and respect of diversity amongst the students. 


\section{Conclusion}

It can thus be concluded that the educational excursion was of value because through the activities from the case study, students became aware of the individual differences other students have. They also became aware of the importance of friendship, improved social interaction, improved positive relationships. These reduced different diverse cultural and language barriers observed prior their involvement in the case study activity.

\section{Recommendations}

From the preceding discussion, it can be recommended that:

- Educational authorities in the country should encourage diversity in the classroom through recommending the use of the relevant content from the text books.

- Institutions of Higher Learning should work-shop teachers and student teachers on how to interact with different children/learners and different communities.

\section{Acknowledgements}

The researcher wish to thank all the University students who actively and voluntarily took part in this research. Without their participation this research was not going to succeed .

\section{References}

Banks, J.A. (1989). The International Companion to Multicultural Education. New York: Routledge.

Crowe, C. Cresswell, K. Robertson, R. Huby, G. Avery, A., \& Sheikh, A. The case study approach. BMC Research Methodology 2011; 11.

Department of Education. (2002). National Curriculum Statement for Grade 10 to12. Pretoria: Department of Education.

Dutton, J. E., \& Heaphy, E. D. (2003). The power of high quality connections at work. In K. Cameron, J. Dutton, \& R. Quinn (Eds.), Positive organizational scholarship: Foundations of a new discipline: 263-278. San Francisco: Berrett-Koehler.

Gravett, S. Merseth, K. K., \& de Beer, J. (2013). Being a Teacher, A Book of Cases. Cape Town: Pearson Education South Africa(Pty) Ltd.

Henning, E, Van Rensburg, W., \& Smit, B. (2004). Finding your way in qualitative research. Pretoria: Van Schaik.

Leonard, M. Graham, S., \& Bonacum, D. The human factor: the critical importance of effective teamwork and communication in providing safe care .Qual Saf Health Care 2004; 13: suppl 1 i85-i90 doi:10.1136.

Merriam, S. B. (2002). Qualitative Research in Practice. San Francisco :Jossey-Bass.

Miller, J. B. (1988). Connections, disconnections, and violations. Stone Center Working Paper Series, Work in Progress. No. 33, Wellesley, MA.

Mouton, J. (2001). How to succeed in your Master's \& Doctoral Studies. A South African guide and Resource book. Pretoria: Van Schawk Publishers.

Rahman, T., \& Spafford, H. (2009). Value of Field Trips for Student Learning in the Biological Sciences.Teaching and Learning Forum, January 2009, Curtin University of Technology.

Sen-Gupta, A. (2003). Changing the focus: a discussion of the dynamics of the intercultural experience. In: Alfred A, Byram M \& Fleming M (eds). Intercultural experience and education. Church Point: Footprint Books.

Vygotsky, L.S. (1978). Mind and Society. Cambridge: Harvard University Press. 